\title{
1-D Coordination Polymers of Organotin(IV) Nodes with Alternating Spacers ${ }^{\dagger}$
}

\author{
Diana-Ioana Eftemie *, Andrei A. Pătraşcu, Cătălin Maxim and Delia-Laura Popescu * \\ Department of Inorganic Chemistry, University of Bucharest, Faculty of Chemistry, 23 Dumbrava Roșie, \\ 020464 Bucharest, Romania; andrei_alunel@yahoo.com (A.A.P.); catalin.maxim@chimie.unibuc.ro (C.M.) \\ * Correspondence: deftemie@yahoo.com (D.-I.E.); delia.popescu@chimie.unibuc.ro (D.-L.P.) \\ † Presented at the 15th International Symposium "Priorities of Chemistry for a Sustainable Development" \\ PRIOCHEM, Bucharest, Romania, 30 October-1 November 2019.
}

Published: 15 October 2019

Keywords: organotin nodes; alternating spacers; coordination polymers

Coordination compounds of organotin(IV) with diverse dimensionalities are obtained due to the ability of the tin atoms to have different coordination numbers, such as 4, 5, 6, or 7 [1].

New 1-D organotin(IV) polymers were obtained starting from triphenyltin chloride $\left(\mathrm{Ph}_{3} \mathrm{SnCl}\right)$ and, concurrently, two different bidentate organic ligands: one having $\mathrm{N}$ donor atoms, such as 1,2bis(4-pyridyl)ethane (bpa) or 4,4' azopyridine (azopy), and the other one having $\mathrm{O}$ donor atoms, such as for example terephthalate (tpa), 2-aminoterephtalate (atpa), or naphthalene dicarboxylate (ndc). Elemental analysis, spectroscopic techniques, such as FTIR and UV-Vis, as well as single crystal and powder X-ray diffraction were used to characterized the obtained compounds.

Five new polynuclear coordination compounds with the general formula $\left\{\left(\mathrm{Ph}{ }_{3} \mathrm{Sn}\right)\left(\mathrm{L}^{1}\right)\left(\mathrm{Ph}{ }_{3} \mathrm{Sn}\right)\left(\mathrm{L}^{2}\right)\right\}_{\mathrm{n}}$, where $\mathrm{L}^{1}=$ bpa and $\mathrm{L}^{2}=$ tpa $($ compound 1$), \mathrm{L}^{1}=$ bpa and $\mathrm{L}^{2}=$ atpa (compound 2), $\mathrm{L}^{1}=$ bpa and $\mathrm{L}^{2}=$ ndc (compound 3 ), $\mathrm{L}^{1}=$ azopy and $\mathrm{L}^{2}=$ tpa (compound 4$)$ and $\mathrm{L}^{1}=$ azopy and $\mathrm{L}^{2}$ $=$ ndc (compound 5, Figure 1) have been synthesized and characterized. The resulting complexes were 1-D coordination polymers in which the triphenyltin(IV) nodes were linked by alternating dicarboxylate and organic diamines ligands. The tin(IV) atoms exhibit a trigonal bipyramidal geometry, with the three phenyl groups in equatorial positions, while $\mathrm{O}$ and $\mathrm{N}$ atoms from the spacers are in apical positions.

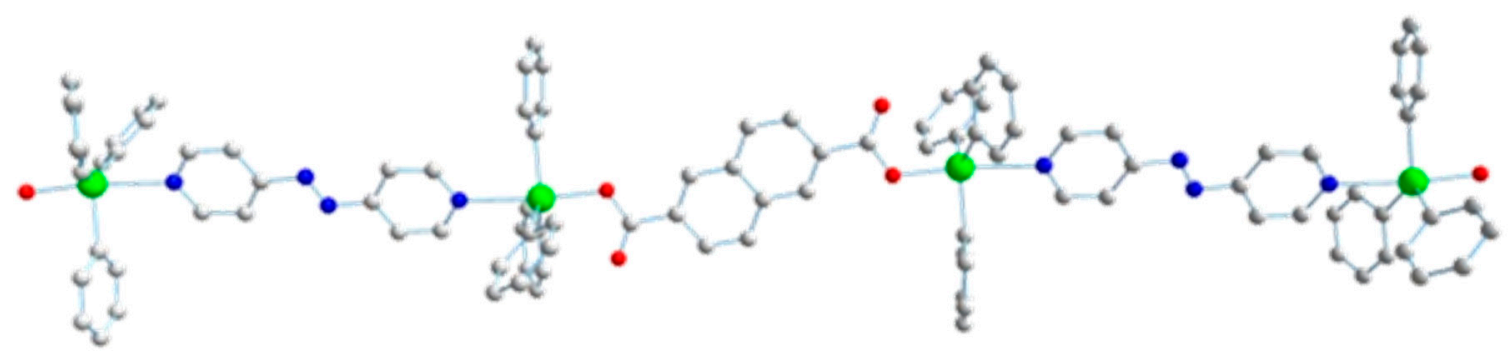

Figure 1. Molecular structure of compound 5. Hydrogen atoms were omitted for clarity.

The resulting compounds showed an interesting and quite rare feature in the chemistry of organotin coordination polymers, namely that the organotin(IV) nodes are connected through alternating ligands ofcarboxylato anions and organic diamines. 


\section{References}

1. Haiduc, I.; Edelmann, F.T. Supramolecular Organometallic Chemistry; Wiley-VCH: Weinheim, Germany, 1999.

(C) 2019 by the authors. Licensee MDPI, Basel, Switzerland. This article is an open access article distributed under the terms and conditions of the Creative Commons Attribution (CC BY) license (http://creativecommons.org/licenses/by/4.0/). 